14. Pagenstecher, A. H.-Uuber Extractionem cataractoser Linser mit ihren Kapsel. Klin. Monatsbl. f. Augenheilk., Vol. III, p. 216, 1865.

15. TraqualR, H. M.-Personal communication.

16. RIDDELL, W. J. B.-Personal communication.

17. Kalt, E. S.-Sur la technique de l'operation de la cataracte. Ann. d'Ocul., Vol. CLX. p. 689, 1923.

18. De l'arrachement de la cristalloide anterieure dans l'operation de la cataracte. Ann. d'Ocul., Vol. CXLII, p. 41, 1910.

19. ARRUGA, H. Les détails techniques de l'extraction intracapsulaire du cristallin. Bull. and Mem. Soc. Frans. d'Ophtal., Vol. XLVI, p. 270, 1933.

20. Castroviejo, R.-Forceps for Intracapsular Extraction. Trans. Amer. Acad. Ophthal., Vol. XLIV, p. 394, 1939.

21. VERHOEFF, F. H.-A New Operation for Removing Cataracts with their Capsules. Trans. Amer. Ophthal. Soc., Vol. XXV, p. 54, 1927.

22. An Improved Capsule Forceps for Intracapsular Extraction. Arch. Ophthal., Vol. XLV, p. 479, 1916.

23. KNAPP, A.-Report of 100 Cataract Exträctions in the Capsule, after Subluxation with the Capsule Forceps. Arch. Ophthal., Vol. XLIV, p. 1, 1915.

24. LANCASTER, W. B.-Discussion of Torok's paper, "Extraction of Cataract in Capsule (v. Graefe's method)," Trans. Amer. Ophthal. Soc., Vol. XIV, p. 482, $1915 . \bullet$

25. ToRoK, E.-Extraction of Cataract in Capsule (v. Graefe's method). Trans. Amer. Ophthal. Soc., Vol. XIV, p. 482, 1915.

26. Stanculeanu, G.-Intracapsulare Staroperationem. Klin. Monatsbl. f. A ugenheilk, Vol. L, p. 527, 1912.

27. Elsching, A.-Extraction of Senile Cataract in the Capsule. Amer. Jl. Ophthal., Vol. VIII, p. 335, 1925.

28. Gradenigo, P.-Sulla estrazione capsule lenticulare. Ann. di Ottal., Vol. XXIV, p. 15, 1895.

29. KiRBY, D. B.-Further Experiences with a System of Intracapsular Cataract Extraction. Trans. Amer. Ophthal. Soc., Vol XLI, p. 61, 1943.

30. Elschnig, A.-Die Intra-Kapsulare Star Extraktion. Berlin. J. Springer. 1933.

31. Sinclair, A. H. H.-The Intracapsular Extraction of Cataract. Trans. Ophthal. Soc. U.K., Vol. LII, p. 57, 1932.

\title{
STUDIES ON THE INTRA-OCULAR FLUIDS* 1.-The Reducing Substances in the Aqueous Humour and Vitreous Body
}

BY

\author{
Sir Stewart Duke-Elder and Hugh Davson \\ OPHTHALMOLOGICÁL RESEARCH UNIT, \\ MEDICAL RESEARCH COUNCIL
}

IN a recent paper to this Journal (Duke-Elder and Davson, 1948) a general review of the present position of our knowledge regarding the nature of the intra-ocular fluids was given; the present paper deals more particularly with our experimental work on the reducing substances (sugars, etc.) in the aqueous humour and the vitreous body. It has long been recognized that the concentration

* From the Department of Physiology, University College, and the Institute of Ophthalmology, London. 
of reducing substances in the aqueous humour is low in comparison with that in the blood plasma (Adler, 1930; O'Brien and Salit, 1931) and the concentration in the vitreous body is still smaller. This has received three explanations.

(1) The low concentration in the ocular fluids has been ascribed to. secretory activity. In view of the metabolic importance of glucose, however, it seems doubtful from a teleological standpoint whether a secretory system would be evolved providing a smaller concentration of this substance than can be produced by a simple mechanical process of filtration. Moreover, the site of such a secretion would presumably be the ciliary epithelium; and the secreted fluid, diffusing from this region through the pupil, would be available to both vitreous body and the anterior chamber so that we should not expect the concentrations in the two compartments of the eye to be significantly different : such a difference, as we shall see, occurs.

(2) Assuming that the aqueous humour is formed, at least partly, by a process of ultra-filtration whereby proteins are left behind to give a comparatively protein-free fluid, if a substance finds some difficulty in passing the barrier between the blood and the cavity of the eye but at the same time can find a free exit, it will be in a deficiency in the aqueous humour in comparison with the blood (Kinsey and Grant, 1942). In this view, the low concentration of glucose would be evidence not of a secretory mechanism in respect to this substance, but rather of the existence of a filtration process.

The mathematical formulation of the problem as set out by these authqrs has been criticised by us (Duke-Elder and Davson, 1944), and recently Palm (1948) has suggested an equation that promises to reconcile the opposing standpoints. We need not confuse the issue in this paper by introducing a mathematical discussion; it is sufficient to state that the effect postulated by Kinsey and Grant is a feasible one, but that it will depend to a great extent on the rate of penetration of the substance concerned. If the substance penetrates slowly and with difficulty, we may expect to find a deficiency of it in the aqueous humour when the steady state is achieved simply because it is drained away too rapidly to be adequately replaced. If the rate of penetration is comparatively rapid, on the other hand, as with ethyl alcohol (Palm, 1948), the effect will be negligibly small. The much lower concentration of glucose in the vitreous body, however, would be difficult to explain on a simple kinetic basis, especially since no flow through this structure has so far been demonstrated.

(3) A third explanation ascribes the deficiency of glucose to its absorption in the metabolic needs of the lens and retina. The lens 
utilises glucose and this must clearly be derived from the aqueous humour and the vitreous body; as the glucose is abstracted from these sources more will diffuse through the blood-aqueous barrier to replace that used up, but since this diffusion process must wait on the utilisation of the sugar to cause the necessary concentration gradient, we must expect a steady state to be established with the concentration lower in the aqueous humour than in the blood plasma. In the case of the posterior cavity of the eye containing the vitreous body, we might not expect to find any greater deficiency since, although this structure is in apposition to the retina which consumes glucose at a great rate, the latter is directly supplied by blood from the capillaries of both the uveal and retinal circulations; there seems little reason why the vitreous body should be involved in this respect. If we assume, however, that the vitreous body receives its glucose, not exclusively by diffusion or secretion from the ciliary body, but rather by diffusion from the capillaries of the retinal and choroidal circulations, then the fact that these capillaries are supplying large quantities of glucose to the retina must influence the concentration in the plasma available for diffusion into the vitreous body. In other words the transudate derived from the choriocapillaris and retinal capillaries is so depleted of sugar that the available concentration for diffusion into the vitreous body is low:

In the present paper it will be shown that the low concentration of glucose in the intra-ocular fluids is predominantly, if not exclusively, a result of the metabolic factors discussed above.

\section{EXPERIMENTAL}

Static Studies. Great care was taken to avoid the hyperglycaemia associated with fear in the experimental animals; nembutal was used as anaesthetic, intraperitoneally in the cat and intravenously in the rabbit. In the latter animal it is impossible to avoid hyperglycaemia, and before fluids were removed the animal was "equilibrated" for some hours with its head projecting from a bleeding-box. For comparison of normal and aphakic eyes this equilibration was not so important and was generally omitted. Blood was withdrawn from the cat by arterial puncture, and from the marginal ear vein of the rabbit after vaso-dilatation with toluene. Sugars were determined in duplicate by the Hagedorn-Jensen technique (1923) on Somogyi (1930) filtrates of the various fluids; sucrose was determined by estimating the reducing value of the fluid before and after hydrolysis in $0.1 \mathrm{NH}_{2} \mathrm{SO}_{4}\left(15 \mathrm{~min}\right.$. at $100^{\circ}$ C. $)$ The difference between duplicates rarely exceeded $1 \%$, except if the reducing value was low when it amounted to $2 \%$. Removal of the lens was carried out by the standard surgical procedure for extracapsular extraction. (Intracapsular extraction is impossible in these animals owing to the adherence of the vitreous to the posterior lens capsule.)

Dynamic Studies. The general principle was to maintain a constant high level of a given sugar in the blood by continuous intravenous infusion of an isotonic solution in $6 \%$ gum acacia under nembutal anaesthesia. Rapid elimination of the injected sugar was prevented by tying the renal arteries. One eye was, in general, removed before the injection, to estimate the initial reducing value of the intraocular fluids, and the other after a known time interval. With sucrose, which is 
estimated independently of the reducing substances in the fluids, the preliminary removal of one eye is unnecessary. After enucleation, the aqueous humour was withdrawn and the eye was then frozen in solid $\mathrm{CO}_{2}$. When hard, the eye was cut into two or more pieces as described later; the frozen pieces of vitreous body were filtered through glass-wool as they melted in order to break down the gel structure. Blood and aqueous humour were immediately placed in tubes surrounded with ice.

\section{Results}

1. Static Studies: the Concentration of Reducing SUBSTANCES.

(a) The normal distribution.

The concentrations of glucose in the aqueous humour, vitreous body, and blood plasma of rabbits and cats are shown in Table I.

TABLE I

GLUCOSE CONCENTRATIONS (MG./100G.H. ${ }_{2} \mathrm{O}$ ) IN PLASMA AND INTRA-OCULAR FLUIDS

\begin{tabular}{|c|c|c|c|c|c|}
\hline & \multirow{2}{*}{ Plasma } & \multicolumn{2}{|c|}{ Fluid } & \multirow{2}{*}{$R_{A}=\mathrm{aq} / \mathrm{pl}}$. & \multirow{2}{*}{$R_{V}=$ vitr.$/ \mathrm{pl}$} \\
\hline & & Aqueous & Vitreous & & \\
\hline Rabbit & $\begin{array}{l}131 \\
133 \\
142 \\
149 \\
160 \\
163\end{array}$ & $\begin{array}{r}116 \\
118 \\
110 \\
128 \\
134 \\
145\end{array}$ & $\begin{array}{l}56 \\
66 \\
74 \\
87 \\
73 \\
82\end{array}$ & $\begin{array}{l}0.89 \\
0.89 \\
0.78 \\
0.86 \\
0.84 \\
0.89\end{array}$ & $\begin{array}{l}0.425 \\
0.495 \\
0.52 \\
0.58 \\
0.46 \\
0.50\end{array}$ \\
\hline Mean & - & - & - & 0.86 & $0: 49$ \\
\hline Cat & $\begin{array}{r}125 \\
89 \\
92 \\
119 \\
104 \\
121 \\
103\end{array}$ & $\begin{array}{l}95 \\
73 \\
78 \\
86 \\
67 \\
89 \\
89\end{array}$ & $\begin{array}{l}64 \\
55 \\
52 \\
61 \\
44 \\
58 \\
64\end{array}$ & $\begin{array}{l}0.76 \\
0.82 \\
0.85 \\
0.72 \\
0.64 \\
0.74 \\
0.87\end{array}$ & $\begin{array}{l}0.51 \\
0.615 \\
0.565 \\
0.51 \\
0.425 \\
0.48 \\
0.62\end{array}$ \\
\hline Mean & - & - & $-'$ & 0.77 & 0.53 \\
\hline
\end{tabular}

It is seen that the concentration of glucose in the aqueous is less than that in the plasma by some 15 to $20 \%$, while that in the vitreous is still less, being approximately half that in the plasma. The results on the cat amply confirm those of Adler (1930); the low glucose content of the vitreous body is striking.

(b) Distribution in the aphakic eye.

There are two main loci of sugar utilization in the eye-the lens 
and retina. That the lens modifies the sugar content of both the aqueous and vitreous humours is shown in Table II, in which some typical results on rabbits and cats are presented. The lens

TABLE II

GLUCOSE CONCENTRATIONS (MG./100 G. H $\mathrm{H}_{2}$ O) IN FLUIDS OF NORMAL AND APHAKIC EYES

\begin{tabular}{|c|c|c|c|c|c|c|}
\hline & \multirow{2}{*}{$\begin{array}{c}\text { Interval } \\
\text { after } \\
\text { extraction } \\
\text { (weeks) }\end{array}$} & \multirow[b]{2}{*}{ Plasma } & \multicolumn{4}{|c|}{ Fluid } \\
\hline & & & $\begin{array}{l}\text { Normal } \\
\text { aqueous }\end{array}$ & $\begin{array}{l}\text { Aphakic } \\
\text { aqueous }\end{array}$ & $\begin{array}{l}\text { Normal } \\
\text { vitreous }\end{array}$ & $\begin{array}{l}\text { Aphakic } \\
\text { vit reous }\end{array}$ \\
\hline Cat No. 1 & $\begin{array}{l}4 \\
6\end{array}$ & $\begin{array}{l}89 \\
98\end{array}$ & $\begin{array}{l}64 \cdot 5 \\
72\end{array}$ & $\begin{array}{l}83 \\
83\end{array}$ & - & - \\
\hline Cat No. 2 & $\begin{array}{l}7 \\
9\end{array}$ & $\begin{array}{r}88 \\
104\end{array}$ & $\begin{array}{l}66 \cdot 5 \\
66 \cdot 5\end{array}$ & $\begin{array}{l}81 \\
83\end{array}$ & - & $\overline{57}$ \\
\hline Cat No. 3 & $\begin{array}{l}3 \\
4 \\
6\end{array}$ & $\frac{95}{88}$ & $\begin{array}{l}76 \\
74 \\
76\end{array}$ & $\begin{array}{l}81 \\
81 \\
82\end{array}$ & $\overline{45}$ & $\frac{-}{53}$ \\
\hline Rabbit No. 1 & $\begin{array}{l}3 \\
5 \\
6 \\
7\end{array}$ & $\begin{array}{l}214 \\
183 \\
185 \\
208\end{array}$ & $\begin{array}{l}165 \\
127 \\
166 \\
157\end{array}$ & $\begin{array}{r}149 \\
99 \\
147 \\
129\end{array}$ & $\frac{-}{99}$ & $\frac{-}{107}$ \\
\hline Rabbit No. 2 & $\begin{array}{l}3 \\
5 \\
6 \\
7\end{array}$ & $\begin{array}{l}161 \\
126 \\
145 \\
178\end{array}$ & $\begin{array}{r}152 \\
103 \\
126 \\
162\end{array}$ & $\begin{array}{l}145 \\
105 \\
121 \\
158\end{array}$ & $\overline{-}$ & $\frac{-}{111}$ \\
\hline Mean ( 9 rabbits) & $7 / 14$ weeks & 152 & 124 & 117 & 87 & 96 \\
\hline
\end{tabular}

was removed from one eye, and at various intervals after the operation, when the eye had quietened down, aqueous humour was withdrawn from both; finally, both eyes were enucleated. In the cat, the increase in the concentration in the aqueous humour after extraction of the lens was pronounced ( $20 \%$ or more) in two cases, whilst in the rabbit it was much smaller; in fact, there may be an actual decrease, as in rabbit No. 1. This seems to be due to diffusion, backwards through the pupil into the vitreous body, since rabbit No. 1 , in which this effect was most marked, had a wide iridectomy and dilated pupil, whereas rabbit No. 2 had no iridectomy, a constricted pupil and some opaque lens matter partially covered the pupillary aperture. Similarly cats Nos. 1 and 2 had portions of opaque lens material remaining in the pupil, whilst in cat No. 3 the pupil was wide and completely unobstructed. - The mean for nine rabbits shows a $6 \%$ decrease in the aqueous humour in the aphakic eye. The vitreous body showed a 
large increase in the cat $(30 \%)$ and a smaller increase in the rabbit. It is to be remembered, however, that the normal eye of the rabbit contains a higher concentration of ascorbic acid than the aphakic eye (Goldman and Buschke,' 1935) and, since this substance contributes to the reducing value of the aqueous humour, and is therefore included in the estimations, the increase in the concentration of glucose in aphakia in this animal is partially masked by the decrease in the concentration of ascorbic acid.

The fact that the fluids of the aphakic eye do not show sugar concentrations equal to that in plasma suggests that the retina is utilizing glucose. If glucose is consumed by the retina of the enucleated eye, the concentration of glucose after incubation should be less in the periphery than in the centre of the vitreous body.

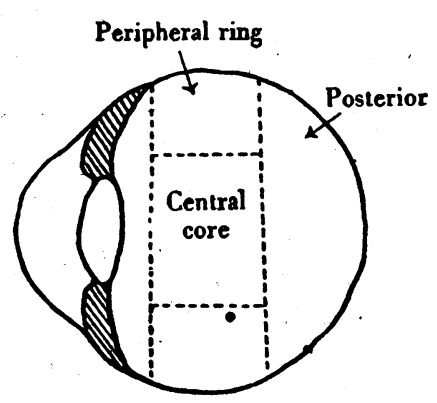

FIG. 1 .

Sectioning of the frozen vitreous before and after incubation.

(c) Concentration in the incubated excised eye.

The two eyes of a cat were removed; one was frozen immediately, while the other was placed in a boiling tube in the bottom of which there was cotton-wool moistened with $0.9 \% \mathrm{NaCl}$; the tube was immersed in a bath at $38-40^{\circ} \mathrm{C}$. After $2 \mathrm{hrs}$. the eye was frozen. The eyes were sectioned as indicated in Fig. 1, giving a large central disk and a thinner posterior cap of vitreous body. With a corkborer the central disk was divided into a core and peripheral ring, the latter about $3 \mathrm{~mm}$. wide. The differences in the glucose contents of the aqueous humour and of the various parts of the vitreous body before and after incubation were as follows :-

\begin{tabular}{c|c|c}
\hline & & $\begin{array}{c}\text { GLUCOSE } \\
\text { DIFFERENCE } \\
\text { mg./100 g. }\end{array}$ \\
\hline Vitreous body & $\left\{\begin{array}{l}\text { Core of central disk } \\
\text { Periphery of central disk } \\
\text { Posterior cap }\end{array}\right.$ & 15 \\
40 \\
30 \\
\hline
\end{tabular}


The result leaves little doubt that the retina is responsible for at least a part of the consumption of glucose in the posterior cavity of the eye. If the lens only were consuming glucose, the core of the icentral disk would have shown the greatest loss since it was in immediate contact with the lens; on the other hand, the greatest loss is in the peripheral regions next to the retina.

In the eye, immediately after enucleation, the glucose is apparently not uniformly distributed through the vitreous body ; Adler (1930) has shown that in the frozen eye the anterior half of the vitreous body contains more sugar than the posterior. In a series of nine rabbits we have found that if the middle disk (Fig. 1 (a)) of the frozen vitreous body was divided into a central core and a peripheral ring, the latter invariably contained the higher glucose concentration. It is possible that these differences in concentration are, at least in part, artefacts resulting from the freezing process, so that it is not justifiable to draw definite conclusions from the observed concentrations regarding the relative extents to which glucose is utilized in the different parts of the eye. The finding of a lower concentration in the central core is, however, reasonable, since it is in immediate contact with the lens. On incubation, however, this relationship is invariably reversed, both in the cat and rabbit; in these circumstances we must assume that the retina draws on the glucose in the vitreous body owing to the absence of the retinal and uveal circulations.

(d) Concentration in mydriasis and miosis, .

A series of experiments were done to determine the concentration of reducing substances in the aqueous humour in mydriasis and miosis. One eye of a cat was treated with eserine and the other with atropine; after about 2 hrs. the aqueous humours were withdrawn from both eyes. The mean results for four cats (two of them kittens) were as follows :

\begin{tabular}{llllllllc} 
& & & & & \multicolumn{3}{c}{$\begin{array}{c}\text { Glucose } \\
\text { mg./100 g. }\end{array}$} \\
Atropinized eye & $\ldots$ & $\ldots$ & $\ldots$ & $\ldots$ & $\ldots$ & $\ldots$ & 70 \\
Eserinized & eye & $\ldots$ & $\ldots$ & $\ldots$ & $\ldots$ & $\ldots$ & $\ldots$ & 75 \\
Plasma & $\ldots$ & $\ldots$ & $\ldots$ & $\ldots$ & $\ldots$ & $\ldots$ & $\ldots$ & 107
\end{tabular}

This rise in the concentration of reducing substances in miosis may, in part, be considered due to a reduction of the area of lens exposed to the aqueous humour. Alternatively, eserine, by breaking down the blood-aqueous barrier, and by increasing the dialysing surface of the iris, may permit a readier penetration of glucose from the blood. It is to be noted that if glucose reaches the anterior chamber by way of a flow from the posterior chamber through the pupil, miosis should restrict this flow and so produce a lower concentration. 
(e) Concentration in the plasmoid aqueous.

Again, it may be expected that the aqueous humour formed immediately after the emptying of the anterior chamber (paracentesis) should have a higher concentration of glucose, since the lens will not have had time to re-establish a steady state. The results of a typical experiment are as follows, the 'second' re-formed aqueous humour being the fluid formed after the successive with'drawals of the original and 'first' re-formed aqueous humour :

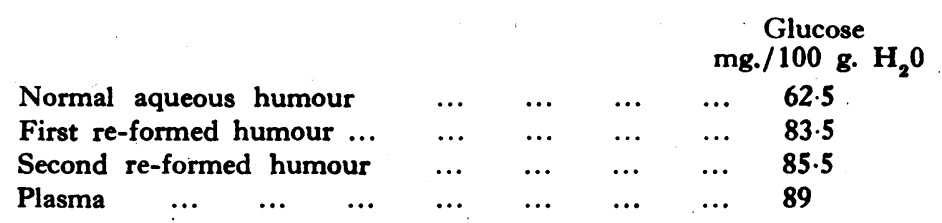

In no instance, however, did the glucose concentration in the re-formed fluid equal that in the plasma.

\section{Kinetic Studies : the Rate of Entry of Reducing Substances.}

The permeability of the membranes of the eye to the following sugars was investigated: glucose, galactose, 3-methyl glucose, xylose and sucrose. 3-methyl glucose is a synthetic compound which is apparently not phosphorylated in vivo (Campbell, unpublished) and was thought, on this account, to be unlikely to be secreted.

Detailed results of seven experiments with glucose are presented in Table III in order that the animal-to-animal variations may be appreciated. Constants indicating the rate of penetration into both aqueous humour $\left(K_{A}\right)$ and vitreous body $\left(K_{V}\right)$ have been calculated in accordance with the equation of Davson and Quilliam (1940).*

Owing to the impossibility of obtaining large supplies of xylose no more than six experiments could be carried out; consequently Student's ' $t$-test' for the differences between means of small samples was applied successively to the mean values of $K_{A} / K_{V}$ for xylose and the individual hexoses; the values of $\mathrm{P}_{S}$ (Yule and Kendall, 1940), indicating the probability that the values of $t$ so computed would occur by chance, are included in the table. With 3 -methyl glucose and galactose the differences in the ratios are significant; with glucose, where greater variability was encountered, the difference is not significant. The large increase of the ratio $K_{A} / K_{V}$ on passing to the disaccharide is clearly significant.

* The equation is only approximate owing to the utilization of sugar by the eye, but in view of the large animal-to-animal variations refinements seem unnecessary. When the plasma reducing value is raised by several hundred per cent. the steady state finally achieved tends to equalitv of concentration expressed as $\mathrm{mg} . / 100 \mathrm{ml}$. as opposed to mg./100 g. $\mathrm{H}_{2} \mathrm{O}$ (i.e., the true concentration in the plasma is about $7 \%$. higher than in the aqueous humour), and for this reason the former unit has been used in these kinetic studies. 
TABLE III

THE RATE OF PENETRATION OF GLUCOSE INTO THE AQUEOUS HUMOUR AND VITREOUS BODY OF THE CAT

\begin{tabular}{c|c|c|c|c|c|c} 
& \multicolumn{2}{|c|}{ Aqueous (mg./100 ml.) } & & \\
$\begin{array}{c}\text { Plasma } \\
\text { (mg./100 ml.) }\end{array}$ & \multicolumn{1}{|c|}{$A_{1}$} & $A_{2}$ & $\begin{array}{c}\text { Time } \\
\text { (hr.) }\end{array}$ & $100 K_{A}$ & $100 K_{V}$ & $K_{A} / K_{V}$ \\
& & & & & \\
\hline & & & & & \\
280 & 94 & 254 & 2.0 & 38 & 11 & 3.45 \\
290 & 140 & 188 & 0.5 & 33 & 16.5 & 2.0 \\
265 & 92.5 & 144 & 0.75 & 20.5 & 12 & 1.7 \\
266 & 130 & 232 & 2.0 & 30 & 10 & 3.0 \\
280 & 104 & 202 & 0.62 & 57 & 7 & 8.1 \\
597 & 112 & 238 & 0.47 & 31 & 10 & 3.1 \\
439 & 88 & 233 & 0.75 & 30.5 & 9 & 3.4 \\
\hline Mean & - & - & - & 34 & 11 & 3.1 \\
\hline
\end{tabular}

In the above table $A_{2}$ is the initial concentration in the aqueous humour; $A_{2}$ the concentration in the aqueous humour after the blood concentration, $P$ had been maintained for $t$ hours. $K_{A}$ is given by the equation :

$$
K_{A}=\frac{k A}{V} \times \frac{1}{2 \cdot 303}=\frac{1}{t} \log \frac{\mathrm{P}-A_{1}}{\mathrm{P}-A_{2}}
$$

where $k$ is the true permeability constant, and $A$ and $V$ are the area and volume of the system respectively. $K_{V}$ represents a similar constant derived from the concentrations in the vitreous body.

TABLE IV

PENETRATION OF DIFFERENT SUGARS INTO THE EYE FLUIDS OF CATS

\begin{tabular}{|c|c|c|c|c|c|c|c|}
\hline Sugar & No. of cats & & $\boldsymbol{K}_{A}$ & $100 \mathrm{~K}$ & $K_{V}$ & $K_{A} / K_{V^{\prime}}$ & $P_{s}$ \\
\hline $\begin{array}{c}\text { Xylose } \\
\text { Glucose } \\
\text { Galactose } \\
\text { 3-Methyl glucose } \\
\text { Sucrose }\end{array}$ & $\begin{array}{l}6 \\
7 \\
9 \\
5 \\
9\end{array}$ & $\begin{array}{l}37 \\
34 \\
33 \cdot 5 \\
36 \cdot 5 \\
4 \cdot 9\end{array}$ & $\begin{array}{l} \pm 2 \cdot 7 \\
\pm 22 \\
\pm 2 \cdot 3 \\
\pm 2 \cdot 9 \\
\pm 0 \cdot 6\end{array}$ & $\begin{array}{c}16.5= \\
11 \\
9.5= \\
11 \\
0.29=\end{array}$ & $\begin{array}{l} \pm 1.5 \\
\pm 0.8 \\
\pm 0.9 \\
\pm 0.5 \\
\pm 0.05\end{array}$ & $\begin{aligned} & 2 \cdot 2 \\
& 3 \cdot 1 \\
& 3 \cdot 5 \\
& 3 \dot{3} \\
& 17\end{aligned}$ & $\begin{array}{l}-\overline{0.125} \\
0.006 \\
0.02 \\
-\end{array}$ \\
\hline
\end{tabular}

$K_{A}$ and $K_{V}$ have the same meaning as for Table $3 . \quad P_{S}$ is the probability that the value of Student's $t$, computed from the mean xylose $K_{A} / K_{V}$ and the hexose $K_{A} / K_{V}$, would occur by chance (Yule and Kendall, 1940). Standard errors are also shown.

Table III shows a consistent difference in rates of penetration into the aqueous humour and vitreous body, the rate for the aqueous humour being some three times greater.' In Table IV the results for the remaining sugars are presented in the form of the constants, $K_{A}$ and $K_{V}$ only. The following points may be noted : 
(a) The rates of penetration of monosaccharides, whether. pentoses (xylose) or hexoses into the aqueous humour are not significantly different; the disaccharide, sucrose, on the other hand, penetrates very much more slowly.

(b) The rates of penetration of the monosaccharides into the vitreous body show a significant difference. The pentose, xylose, shows the most rapid entry, a little over one-half its rate of penetration into the anterior chamber $\left(K_{A} / K_{V}=2 \cdot 2\right)$. The rates of penetration of the hexoses are all of the same order-about one-third of those into the aqueous humour $\left(K_{A} / K_{V}^{\prime}=3 \cdot 1\right.$ to 3.5$)$. In the case of sucrose, penetration is very small indeed; the factor is one-seventeenth $\left(K_{A} / K_{V}=17\right)$.

The results suggest that the barrier separating the blood plasma from the vitreous body is more selective than that separating it from the aqueous humour; thus the latter apparently does not discriminate between a hexose and pentose, whereas the former appears to do so; as the molecular size is increased the greater selectivity of the barrier separating the vitreous body from the blood is shown in the increasing value of $K_{A} / K_{V}$.

The Site of Entry. The differing relative values of $K_{A}$ and $K_{V}$ for any given sugar suggest that this substance can enter the eye from other regions than the ciliary body; if penetration took place only from the ciliary body-it would be expected that, after maintaining the blood sugar level at a high value for (say) an hour,

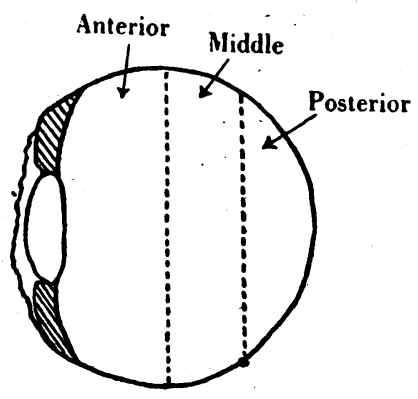

FIG. 2.

Sectioning of the frozen vitreous body before and after diffusion experiments, the aqueous humour having been removed.

the concentration in the part of the vitreous body most remote from the ciliary body would be smaller than in that nearest. In thirteen different experiments, the eyes, after removal of the aqueous humours, and freezing, were cut approximately as in Fig. 2; these gave as mean volumes for the various sections : 
posterior, $0.35 \mathrm{ml}$., middle, $0.43 \mathrm{ml}$., and anterior, $0.63 \mathrm{ml}$. The different parts were analysed and the results are shown in Table V. It will be seen that, for the control eyes, the mean concentration in the middle section was $67 \mathrm{mg} \cdot / 100 \mathrm{~g} . \mathrm{H}_{2} 0$, being $92 \%$ of that in the posterior section; after a high blood-sugar had been

TABLE V .

CONCENTRATIONS OF SUGAR (MG./100,G. $\mathrm{H}_{2} \mathrm{O}$ ) IN THREE SECTIONS OF VITREOUS BODY AFTER MAINTAINING A HIGH BLOOD CONCENTRATION FOR A DEFINITE PERIOD, COMPARED WITH THE CONCENTRATION IN THE CONTROL EYE. MEAN RESULTS OF THIRTEEN EXPERIMENTS

\begin{tabular}{c|r|c|c}
\hline & \multicolumn{3}{|c}{ Section of vitreous body } \\
\cline { 2 - 3 } & Posterior & Middle & Anterior \\
\hline Control & $73-$ & 67 & 75 \\
Test & 124 & 98 & 113 \\
\hline
\end{tabular}

maintained for about $1 \mathrm{hr}$. the average concentration in the middle section was $98 \mathrm{mg} . / 100 \mathrm{~g} . \mathrm{H}_{2} \mathrm{O}$, being only $78.5 \%$ of that in the posterior section. The results certainly suggest that the locus of diffusion into the vitreous body is not confined to the ciliary body, but occurs throughout the whole posterior segment of the eye. It must be remembered, however, that deductions from the concentrations of dissolved material in the frozen eye are to be accepted with caution. To minimize any such fallacy, conditions of freezing were kept as uniform as possible so that disturbances in distribution would operate to the same extent in the control and test eyes, and it would seem that the results are significant.

These results prompted an inquiry into the site of entry of substances into the aqueous humour; if diffusion takes place entirely from the ciliary body, they must enter the anterior chamber through the pupil; and a variation in the size of the latter might modify the rate of appearance. Diffusion experiments - were carried out as before, but one eye of the cat was eserinized and the other atropinized. If diffusion takes place only from the ciliary body the rate of entry should be less in the eserinized eye with its extremely narrow slit-like pupil. The results are shown in Table VI and confirm those in the concentration experiments previously recorded; invariably the rate of entry of sugar into the eserinized eye was more rapid than into the atropinized eye.

These results strongly suggest that the primary effect of eserine on the penetration of sugars into the eye is to diminish any block to the passage of sugar presented by the blood-aqueous barrier 
TABLE VI

THE RELATIVE RATES OF ENTRY OF SUGARS INTO ATROPINIZED AND ESERINIZED EYES

\begin{tabular}{l|c|c|c}
\hline Sugar & $\begin{array}{c}\text { Time } \\
(\mathrm{min})\end{array}$ & $\begin{array}{c}\text { Atropinized } \\
\text { eye }\end{array}$ & $\begin{array}{c}\text { Eserinized } \\
\text { eye }\end{array}$ \\
\cline { 2 - 3 } $\begin{array}{l}\text { Galactose } \\
\text { Galactose }\end{array}$ & 40 & 152 & 214 \\
Glucose & 60 & 215 & 239 \\
Xylose & 41 & 242 & 257 \\
Galactose & 62 & 191 & 199 \\
Sucrose & 150 & 164 \\
Sucrose & 110 & 18 & 28 \\
& & 38 & 51 \\
\hline
\end{tabular}

The figures represent sugar concentration in the aqueous humour, in $\mathrm{mg} . / 100 \mathrm{~g} . \mathrm{H}_{2} \mathrm{O}$, after maintaining a high sugar concentration in the blood for a given time.

(as, for example, by inducing vaso-dilatation) and/or to increase the area across which passage is possible (the surface of the iris). If such were its effect, we should expect the influence of the drug to be greater proportionately on a substance that penetrates the bàrrier with difficulty. The bracketed results in Table 6 , which describe the effect of eserine on the penetration of both galactose (penetrating comparatively easily) and sucrose (penetrating with difficulty) show that this effect is clearly much stronger with the latter substance. On purely mechanical grounds we should expect a less reådy flow of aqueous humour through the pupil when the latter is a mere slit, and the fact that sugars actually penetrate into the anterior chamber at a faster rate would suggest either that flow through the pupil is not affected by its size or that the partial breakdown of the blood-aqueous barrier or an increase in its area obscures any effect of diminished flow.

\section{Discussion}

There seems little doubt from the results of the first part of this paper that metabolic factors play an important part in determining the low concentration of reducing substances in the intra-ocular fluids. The influence of the lens is seen in the higher concentration in aphakic eyes; but in these the aqueous humour and plasma levels still differ by a factor of some $10 \%$ in the cat.

From the observed concentrations and the constant, $K_{A}$ for glucose, it is possible to calculate the rate of absorption of glucose from the anterior chamber; it amounts to about $0 \cdot 15 \mathrm{mg} . / \mathrm{hr}$., a figure not inconsistent with the known sugar utilization of the 
lens (Kronfeld and Bothman, 1928). From the posterior cavity of the eye the lens and retina may both extract glucose, and the concentration in the vitreous body is therefore less than in the aqueous humour. The regional distribution of glucose in the vitreous body is explained by this dual consumption. The aqueous humour immediately re-formed after paracentesis has a glucose concentration differing by only about $5 \%$ from that of plasma; here the effects of the activity of the lens and diffusion through the pupil are minimized, and one might expect to find the concentrations equal. Three factors, however, must be taken into consideration. In the first place, a small fraction of the sugar in the blood is probably bound to the proteins of the plasma and is therefore not free to diffuse across a membrane impermeable to protein. In the second place, the blood used for comparison was arterial; the eye is an organ with a very high metabolism and we may therefore expect an arterio-venous difference in sugar concentration. It is to be remembered that differences as large as 39 $\mathrm{mg} . / 100 \mathrm{~g}$. between the blood-sugar content of the carotid artery and vortex vein have been reported; the greater portion of this discrepancy is probably due, however, to activity in the more posterior parts of the eye. The glucose concentration in the capillary plasma is almost certainly, on the average, less than that in arterial plasma. Finally, the non-sugar reducing substances in the plasma represent a considerable fraction of the whole (27 $\mathrm{mg} . / 100 \mathrm{ml}$. according to Somogyi, 1927); the membrane separating the aqueous humour from the plasma has a high degree of selectivity in respect to nitrogenous compounds (unpublished) and it is possible that the re-formed aqueous humour, formed by a rapid process of ultra-filtration and therefore not necessarily equivalent to a dialysate, contains a lower concentration of nonsugar reducing substances than would be the case if time were permitted for dialysis to proceed to completion. The behaviour of sucrose is a case in point; if a high sucrose concentration is maintained in the blood of the cat, it is found that the re-formed aqueous humour after paracentesis has a sucrose concentration only $60 \%$ of that in the blood.

This consideration brings us to the viewpoint put forward by Kinsey and Grant (1942); according to their treatment, the deficiency of glucose in the aqueous humour is due to the difficulty of entry of this molecule during a filtration process and the freedom of its exit in the drainage of aqueous humour from the anterior chamber. That such a retention is theoretically feasible we have indicated in the introduction to this paper and is moreover confirmed by the experiment on sucrose described above; sucrose, however, penetrates the eye with great difficulty, whereas glucose enters at a rate some seven times greater. Without an exact mathematical analysis, which so far has not been made owing to the difficulty in assessing one of the parameters in the process, it is not possible to state on theoretical grounds whether the effect of this retention will manifest itself measurably in respect to glucose. As we have indicated earlier, we have some evidence that 
when the blood sugar level is raised considerably, so that metabolic consumption becomes proportionately less significant, glucose penetrates the eye and approaches a steady state in which the concentration, expressed as $\mathrm{mg} .100 \mathrm{~g} \cdot \mathrm{H}_{2} \mathrm{O}$, is some $7 \%$ lower than in the plasma. This suggests that the effect of retention is measurable in the case of glucose, but that it is by no means sufficient to account for the $23 \%$ difference pertaining in the normal animal.

It is difficult to assess experimentally the true steady-state with glucose since a high blood sugar concentration must be maintained over a period of hours; and during the last hour this cortcentration must be kept constant. The matter is further complicated by the non-specificity of the usual methods for determining sugars. So far as the aqueous humour is concerned, therefore, we may say that the low concentration of glucose is due mainly, if not entirely, to metabolic factors; the retention factor of Kinsey and Grant, whereas it probably plays an important rôle in the steady-state achieved by sucrose and other substances penetrating more slowly, is not the determining factor with respect to glucose.

With urea, on the other hand, it would seem that for the low concentration, described first by. Adler (1933), and later confirmed by a number of authors and also in our laboratory, the explanation of Kinsey and Grant is at least theoretically valid; urea penetrates at less than half the rate of glucose (Davson, Duke-Elder, Maurice, Ross and Woodin, 1949), and here metabolic influences may be ruled out.

The kinetic studies tend to confirm this view of the steady-state; the barrier between the plasma and the aqueous humour shows no special selectivity towards glucose but permits galactose, the synthetic 3-methyl glucose, and the pentose, xylose, to pass at about the same rate. If any secretory activity were involved, one might expect, by analogy with intestinal absorption, to. find appreciable differences in rates, particularly in the case of the synthetic sugar which we might not expect to be secreted at all and certainly not at the same rate as glucose. The slow rate of penetration of sucrose is in agreement with some earlier preliminary work on the dog (Weld, Feindel and Davson, 1942) in which it was shown that this molecule represents the limiting size for sugar penetration, the trisaccharide, raffinose, hardly penetrating at all. So far as these results go, it would appear that a purely physical explanation of diffusion depending on molecular size, meets the case.

The striking difference in selectivity between the barriers separating the aqueous humour and vitreous body from the blood is of some significance; hitherto it has been considered sufficient, in the interpretation of intra-ocular dynamics, to study the penetration of substances into the aqueous humour only. The existence of this more selective membrane lining the posterior cavity of the eye may well mean that the composition of the vitreous body plays a part of some importance in the determination of the intra-ocular pressure; if there is any secretion into the eye 
it will obviously be more effective in modifying any difference between the osmotic pressures of the ocular fluid and plasma if the secreted substance does not leak away rapidly.

The question may reasonably be raised whether the differences in $K_{A}$ and $K_{V}$ represent actual differences in permeability constants. The constants $K_{A}$ and $K_{V}$ contain the factor $A / V$, the ratio of area of membrane to volume of fluid, and if this is not the same for the two compartments of the eye the constants are not directly comparable. In the cat, the volumes of aqueous humour and vitreous body are roughly in the ratio of $1: 1 \cdot 5$, but it is impossible to state the effective areas of membrane; in view of the large number of ciliary processes, it would appear that the area available for diffusion into the vitreous body is considerably the greater, in which case the difference between the true permeability constants would be greater still. It is not necessary, however, to know the values of $A / V$ in determining whether the differences in $K_{A}$ and $K_{V}$ represent differences in permeability constants; if the membranes had identical characteristics we should expect the ratio $K_{A} / K_{V}$ to be the same for different molecules; as we have seen, this is by no means true for the ratio increases with increasing size of molecule. In a similar way, the effects of different viscosity and different rates of mixing in the two fluids should manifest themselves to approximately the same extent for different molecules.

It is of interest to assess the actual value of $k$, the true permeability constant for hexoses, from an assumed area-to-volume relationship. $k$ is given by:

$$
k=\frac{K V}{A} \times 2.3 \text { (Davson and Quilliam, 1940). }
$$

Conventionally, $k$ is expressed as the number of g.-mol. of the substance penetrating $1 \mu^{2}$ of surface in 1 sec. when the concentration difference is $1 \mathrm{~mol} . / 1$. If the volume of the aqueous humour is taken as $1 \mathrm{ml}$. and the diffusing surface as $1 \mathrm{~cm} .^{2}, k$ comes out at approximately $2 \times 10^{-15}$. This compares with a value of $7.8 \times 10^{-16}$ for the penetration of urea into the ox erythrocyte, an instance of high permeability. The effective area of diffusing surface for the anterior chamber is, of course, likely to be very much higher than $1 \mathrm{~cm} .^{2}$; if the area-to-volume relationship were comparable with that in the erythrocyte where $1 \mathrm{ml}$. of cells has an area of about $1 \times 10^{12} \mu^{2}$ (Ponder, 1934), $k$ becomes $2 \times 10^{-19}$. Such an extreme instance of area-to-volume relationship is unlikely to apply to the eye, but even this value of $k$ suggests that the rate of penetration is comparatively high when it is appreciated that the penetration of the smaller molecule, erythritol, into plant cells gives constants ranging from $7 \times 10^{-21}$ to $1.3 \times 10^{-19}$ (vide Davson and Danielli, 1943).

It therefore seems likely that the penetration of hexoses into the eye is a rapid permeability process; this fact, and the absence of a significant difference in rate between hexoses and the pentose, might suggest a penetration by way of water-filled pores, e.g., through the intercellular spaces of the iris capillaries and iris endothelium. Evidence derived from a study of the penetration of some other substances, however, is against this simple mechanism and it is more probable that the comparatively. rapid rate of penetration of sugars is an instance of cell membrane specialization of the kind described by Davson and Reiner (1942).

In conclusion we feel we must draw attention to the significance of the results of kinetic experiments and their mathematical formulation. In our treatment of the process of penetration of sugars into the eye we have applied purely kinetic principles such as 
would apply to the migration of substances across an inert membrane; the complications introduced by a possible flow of aqueous humour, as first pointed out by Kinsey and Grant (1942) and modified by Duke-Elder and Davson (1943) and Palm (1948), in no way affect the fundamental principles of the kinetic treatment provided that there is a sufficient head of pressure in the blood capillaries to make the postulated concentration differences feasible. The existence of a flow of aqueous humour through the pupil and out at the angle of the anterior chamber has been abundantly demonstrated by clinical observations, by the recent observations of Ascher on aqueous veins (1942) and by a variety of experimental procedures on laboratory animals (Friedenwald and Pierce, 1932, and Bárány and Kinsey* on the rabbit : Davson, Duke-Elder and Maurice, unpublished, on the cat): this will be made the subject of another paper but, in general, it would seem that the aqueous humour is replaced at a rate of some 1 to $2 \%$ of its volume per minute. Such a flow could, theoretically, be maintained by a simple mechanical filtration process although the work of Bárány $(1946,1947, a, b, c, 1948)$, makes this doubtful. Moreover, evidence has been accruing from this laboratory that secretory processes are at work in the elaboration of (at any rate) certain constituents of the aqueous humour (Duke-Elder and Davson, 1948) : thus the osmotic pressure of the aqueous humour is greater than that of plasma "(Benham, Duke-Elder and Hodgson, 1938), as also is its content of sodium and chloride (Hodgson, 1938: Davson, 1939: Davson and Weld, 1940 : Davson, Duke-Elder and Maurice, 1949).

As Bárány and Davson (1948) have emphasised, equations derived to explain the penetration of substances by a secretory mechanism (e.g., that of Kinsey and Grant, 1942) have essentially the same form as those derived on a simple kinetic basis once the factor of drainage is introduced; there is thus nothing in the kinetics of the penetration of the various substances so far studied, considered as evidence by itself, that need necessarily rule out the secretory view of the mode of formation of the aqueous humour. In view of the arbitrary assumptions necessary for the formulation of equations dealing with secretory processes, arguments on purely kinetic grounds tend to be sterile, and more subtle and discriminating modes of investigation are necessary.

\section{Summary}

1. In the cat and rabbit, the glucose concentrations in the aqueous humour and vitreous body are lower than would be

* Personal communication from Dr. Bárány. 
expected on the basis of a simple diffusion equilibrium with the plasma. Experiments indicate that this deficit of glucose is due to the metabolism of both the lens and the retina.

2. The rates of penetration of glucose, galactose, 3-methyl glucose, xylose and sucrose into both aqueous humour and vitreous body of the cat's eye have been measured, and constants, $K_{A}$ and $K_{V}$, proportional to these rates, have been calculated. No significant differences in rate of penetration into the aqueous humour were found with the first four sugars; but sucrose (a disaccharide with a larger molecule) penetrated much more slowly : polysaccharides (inulin, raffinose) cannot cross the bloodaqueous barrier in significant amounts in the normal state. The penetration rates of all sugars into the vitreous body were consistently smaller than into the anterior chamber, and an analysis of the results indicates the existence of a more selective barrier to diffusion into this part of the eye than that separating the aqueous humour from the blood. The possible physiological significance of this difference is discussed and the importance of including the vitreous body in any study of intra-ocular dynamics is stressed.

3. The rates of penetration of sugars into the aqueous humour with a constricted and a dilated pupil have been studied and it seems likely that a considerable amount of diffusion into the anterior chamber takes place from the iris. Evidence is presented which suggests that the locus of diffusion into the vitreous body is not confined to the ciliary body but occurs from all the surrounding vascularized tissues.

4. It would appear that the entry of sugars into the eye can be explained on the basis of a process of diffusion. That secretory activity is not involved in the process (so far as these substances are concerned) is suggested by $(a)$ the variation of the rate of entry with the molecular size of the substances concerned, $(b)$ the similarity of the rate of entry of natural sugars (e.g., glucose) with synthetic sugars not found or phosphorylated in the body (3-methyl glucose), and (c) the evidence that sugars enter the ocular cavity from all the surrounding vascularized tissues.

5. By assuming limiting values for the area-to-volume relationship for the aqueous humour, it is possible to calculate the true permeability constants for the hexoses in the conventional units; the computation suggests that penetration is rapid in comparison with that of analogous lipoid-insoluble molecules diffusing into plant cells.

We are grateful to the Medical Research Council for defraying the whole cost of this work. We should also like to thank Prof. Lovatt Evans for extending us the hospitality of his laboratory. 


\section{REFERENCES}

AdLer, F. H. (1930).-Trans. Amer. Ophthal. Soc., Vol. XXVIII, p. 307. (1923).-Arch.f. Ophthal., Vol. X, p. 11.

Ascher, K. W. (1942).-Amer. Jl. Ophthal., Vol. XXV, pp. 31, 1174, 1301, 1309.

BÁrÁNy, E. H. (1946).-Acta Ophthal. (Copenhagen), Vol. XXIV, p. 337.

- (1947a).-Acta Ophthal. (Copenhagen), Vol. XXV, p. 81.

(1947b).-Acta Physiol. Scand., Vol. XIII, pp. 55-61.

(1947c).-Ibid., Vol. XIII, p. 81.

(1948).-Ophthalmologica, Vol. CXVI, p. 65.

BÁrÁNy, E. H. and Davson, H. (1948).-Brit. Jl. of Ophthal., Vol. XXXII, p. 313.

Benham, G. H., Duke-Elder, W. S. and Hodgson, T. H. (1938).-Jl. Physiol., Vol. XCII, p. 355.

Davson, H. (1939).-Jl. Physiol., Vol. XCVI, p. 194.

Davson, H. and Danielli, J. F. (1943). - The Permeability of Natural Membranes. Cambridge University Press.

Davson, H. and Quilliam, J. P. (1940) - Jl. Physiol., Vol. XCVIII, p. 141.

Davson, H. and Reiner, J. M. (1942).-Jl. Cell. Comp. Physiol., Vol. XX, p. 325.

Davson, H. and Weld, C. B. (1940).-Amer. Jl. Physiol., Vol. CXXXIV, p. 1.

Davson, H., Duke-Elder, W. S. and Maurice, D. M. (1949).-Jl. Physiol., in press.

Davson, H., Duke-Elder, W. S., Maurice, D. M , Ross, E. J. and Woodin, A. M. (1949).-Jl. Physiol., in press.

Duke-Elder, W. S. and Davson, H. (1943).-Brit. Jl. of Ophthal., Vol. XXVII, p. 431.

(1948).-Brit. Jl. of Ophthal., Vol. XXXII, p. 535.

Friedenwald, J. S. and Pierce (1933).-Arch.: of Ophthal., Vol. VII, p. 538 ; Vol. VIII, p. 9.

Goldman, H. and Buschke, W. (1935).-Klin. Woschr., Vol. XIV, p. 239.

HAGEDORN, H. C. and JENSEN, B. N. (1923).-Biochem. Zeitschr., Vol. CXXXV, p. 46.

Hodgson, T. H. (1938).-Jl. Physiol, Vol. XCIV, p. 118.

Kinsey, V. E. and Grant, M. (1942).-Jl. Gen. Physiol., Vol. XXVI, p. 131.

Kinsey, V. E., Grant, M. and Cogan, D. G. (1942).-Arch. of Ophthal., Vol. XXVII, p. 242.

Krönfeld, P. and Bothman, L. (1928).-Zentralbl. f. Augenheilk., Vol. LXV, p. 41.

O'Bkien, C. S. and Salit, A. W. (1931).-Amer. Jl. Ophthal., Vol. XIV, p. 582.

PALM, E. (1948):-Acta. Ophthal., Vol. XXV, p. 139.

Ponder, E. (1934).- The Mammalian Cell and the Properties of Haemolytic Systems. Berlin, Borntraegar.

Sомоgyı, M. (1927).-Jl. Biol. Chem., Vol. LXXV, p. 33. (1930).-Ibid., Vol. LXXXVI, p. 65.5.

Weld, C. B., Feindel, W. H. and Davson, H. (1942).-Amer. Jl. Physiol., Vol. CXXXVII, p. 421.

YULE, G. U. and KENDALL, M. G. (1940).-An Introduction to the Theory of Statistics. London, Griffin. 